Lepr Rev (1982) 53, 45-65

\title{
Immunological implications of necrotic, cellular and vascular changes in leprous neuritis: light and electron microscopy
}

\author{
D K DASTUR, ${ }^{*}$ G L PORWAL, ${ }^{*} \mathrm{~J} \mathrm{~S} \mathrm{SHAH}^{\dagger} \&$ \\ C R REVANKAR ${ }^{\dagger}$ \\ *The Neuropathology Unit, Grant Medical College and J. J. \\ Group of Hospitals, Bombay; †Acworth Leprosy Hospital, \\ Bombay
}

\section{Received for publication 12 May 1981}

Summary. The fine structural changes and, to a lesser extent, histochemical and histopathological features of biopsy specimens of nerves from patients with non-lepromatous leprosy (mainly very early cases), or lepromatous leprosy (mostly treated cases), have been studied from the point of view of possible immunological response of the host tissues. Using electronmicroscopy and acid phosphatase or B-glucuronidase as markers of lysosomal enzymes, the survival and degradation of Mycobacterium leprae by Schwann cells and macrophages in the nerves is compared, both these cells utilizing the lysosomal machinery for such degradation, the macrophages more strongly, once the individual bacillary space has been breached. Longtreated lepromatous patients show relatively fewer intact and more degenerating bacilli. Both live and killed $M$. leprae appear to provide antigenic material, and plasma cells as well as activated macrophages harbouring considerable rough ER, probably produce antibodies and lysosomal enzymes.

Impressive, fine structural changes in clinically well-preserved nerves from patients with very early non-lepromatous leprosy, as well as those with overtly tuberculoid and untreated or treated lepromatous leprosy, included the appearance of products of breakdown of nerve fibres, particularly of myelin, vacuolated macrophages among the fibres; and changes in the intraneural blood vessels such as loosening of the endothelial-tight junctions, proliferation of basement membrane and exudation of plasmatous material perivascularly. On the basis of these findings 3 possible non-bacterial antigens producing damage to nerve parenchyma are considered: (i) myelinogenous proteins which are known to evoke allergic neuritis and further

¥Correspondence: Professor Darab K Dastur, Director, Department of Neuropathology and Applied Biology, MRC, 15th Floor, Bombay Hospital, 12 Marine Lines, Bombay-400 020, India. 
myelin destruction, as an autoimmune mechanism; (ii) the vascular basement membrane material which is mainly a protein, like reticulin; and (iii) plasma proteins, especially when containing high, circulating levels of antibodies.

\section{Introduction}

This paper represents a revised and updated version of a talk given at the International Symposium on Immunological Aspects of Leprosy and other Mycobacterial Diseases, held at Delhi in November 1977 (unpublished). A considerable amount of nerve biopsy material collected since then is now included. The emphasis in this paper will not be on a mere detailing of the changes in nerves in one or another type of leprosy, which have been reviewed elsewhere, ${ }^{1,2}$ but rather an evaluation of the functional significance of the changes, mainly at the fine structural level, in various constituents of the peripheral nerve. Stress will be particularly laid on the necrotic changes in and around the blood vessels and in the Schwann cells, the nature of the inflammatory reaction evoked, particularly in very early non-lepromatous leprosy and in treated lepromatous patients, and the fine structure of macrophages.

\section{Material and methods}

The material is drawn mainly from 4 groups of cases, briefly outlined below, examined clinically and bacteriologically, surgically explored and biopsied at Acworth Leprosy Hospital, during 1976-9.

\section{CLINICAL MATERIAL}

Group I included 8 patients with very early non-lepromatous leprosy, mostly of the early macular tuberculoid variety. All patients were bacteriologically negative and had only 1 or 2 small, flat, hypopigmented and hypaesthetic to anaesthetic skin lesions of recent origin. A biopsy of these lesions showed only small inflammatory exudates in the dermis, made up of lymphocytes with stray large mononuclear cells, but no giant cells, lepra cells or bacilli. None of the patients had any signs or symptoms referable to the peripheral nerves, except in 1 patient where there was slight tenderness of the ulnar nerve.

Group II was made up of 3 patients with established untreated tuberculoid leprosy of long duration. They were all bacteriologically negative on examination of smears of full thickness skin biopsies. Two of them had small or large pale anaesthetic skin lesions, occasionally with raised edges. Paraffin sections of 
these showed more florid mononuclear cell reaction than in patients of Group I. While 2 patients had moderate thickening and enlargement of nerves in the arms, the third patient had no detectable skin lesions but marked thickening and tenderness of both ulnar and lateral popliteal nerves. The expected sensory impairment and muscular weakness were found in these patients.

Group III consisted of 3 patients with untreated lepromatous leprosy. They were bacteriologically postive with a large number of acid-fast bacilli (AFB) in both skin clip and nasal smears. There were no discrete lesions but there was generalized infiltration of the skin, and therefore biopsy specimen of the skin from the edge of the incision on the hand was examined. This showed a few exudates with lepra cells and small mononuclear cells. The ulnar, greater auricular, sural or other nerves were found to be thickened and tender.

Group IV included only 8 treated lepromatous patients, who had taken the prescribed course of treatment with dapsone (DDS), usually $600 \mathrm{mg}$ a week continuously for $1 \frac{1}{2}-6$ years. The dapsone/creatinine ratio in urine was found to be within normal limits (35 and over) in 7 patients, and markedly low in only 1 patient, indicating that he was not taking the prescribed dose. All patients showed many AFB, mainly granular forms, in skin clips and nasal smears. The ulnar nerve was found thickened in all patients and in 1 case the radial and lateral popliteal nerves also.

The muscular weakness or wasting encountered in patients of Groups II, III and IV, has been outlined elsewhere. ${ }^{3}$

\section{SURGICAL PROCEDURE}

In 5 of the patients of Group I, a medial funiculus of the ulnar nerve just above the elbow was biopsied, since this is the most frequently involved nerve in leprosy. In the remaining patients the index branch of the radial cutaneous nerve on the dorsum of the hand was biopsied, keeping in mind the fact that this nerve is also frequently involved in all types of leprosy. The plastic surgeon (J S S) was assisted at surgery by the Professor of Neuropathology (D K D) and the leprologist ( $\mathrm{C} \mathrm{R} \mathrm{R}$ ). Care was taken not to stretch the nerve or to lift it completely off its bed just prior to excision of a $5-6 \mathrm{~cm}$ length of the funiculus (of the ulnar nerve) or the entire nerve. It was immediately divided and transferred to different vials with appropriate fixatives for histochemical, electronmicroscopic and histological examination.

\section{LABORATORY METHODS}

Histochemical demonstration of acid phosphatase was carried out by Gomori's method $^{4}$ and of B-glucuronidase by the method of Hayashi et al. ${ }^{5}$ on frozen sections.

Paraffin sections were stained routinely with haematoxylin and eosin, 
Gomori's reticulin stain, the picro-Mallory procedure for connective tissue and myelin, Holmes's silver method for axons, and Fite-Faraco's method for acidfast bacilli.

The essential steps for ultramicrotomy and electronmicroscopy (EM) were the collection and immediate fixation of small longitudinally oriented pieces in cold $4 \%$ glutaraldehyde in Millonig's phosphate buffer, post-fixation in $\mathrm{OsO}_{4}$, dehydration in a graded series of ethyl alcohol and blocking in araldite. The blocks were sectioned by glass knives; semithin $(1 \mu \mathrm{m})$ sections were obtained and stained with toluidine blue for survey. Silver-grey thin sections were collected on copper grids for examination on a Phillips EM200 Electromicroscope.

\section{Observations}

Findings in patients with very early non-lepromatous leprosy (Group I) and in cases with treated lepromatous leprosy (Group IV) will be stressed. A couple of relevant illustrations will also be given from cases not included in the above material.

The material is best considered under 2 headings: reactive and degenerative changes in and around the Schwann cells; and the vascular and inflammatory cell changes, mainly of macrophages.

\section{REACTIVE AND DEGENERATIVE CHANGES RELATED TO SCHWANN CELLS}

The metabolic activity which still-viable Schwann cells put forth non-specifically in any peripheral nerve disorder, infectious, allergic, toxic or traumatic, can be readily detected by a delineation of the activity of a lysosomal enzyme such as acid phosphatase. This has been discussed earlier elsewhere. ${ }^{1,6,7}$ The activity is spotty and mainly paranodal along the Schwann cell pathways, as illustrated in the above references. When inflammatory cells infiltrate the nerves, in both tuberculoid and lepromatous leprosy, the macrophages also manifest lysosomal activity, as seen with B-glucuronidase in Figure 1 (a). If the Schwann cells have degenerated and been replaced by collagenous tissue, as in this specimen, then no activity is seen in the Schwann tubes. The disorganization of the endoneurium and Schwann cell pathways and the proliferation of blood vessels which takes place in such nerves, is well revealed by Gomori's reticulin stain (Fig. 1 (b)).

Even in clinically unaffected nerves, as from very early cases of Group I, where only 1 or 2 skin lesions gave evidence of non-lepromatous leprosy, some reaction and degeneration of the Schwann cells was encountered in nerve biopsy specimens (Fig. 2 (a)). In Figure 2 (b), of a nerve from such a patient, 


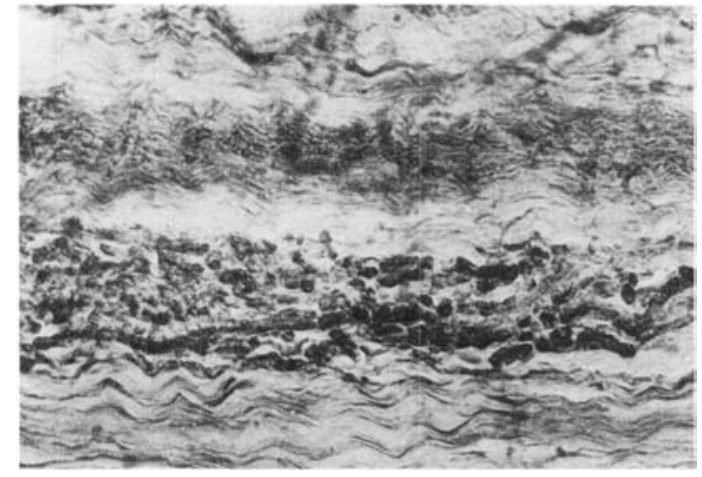

a

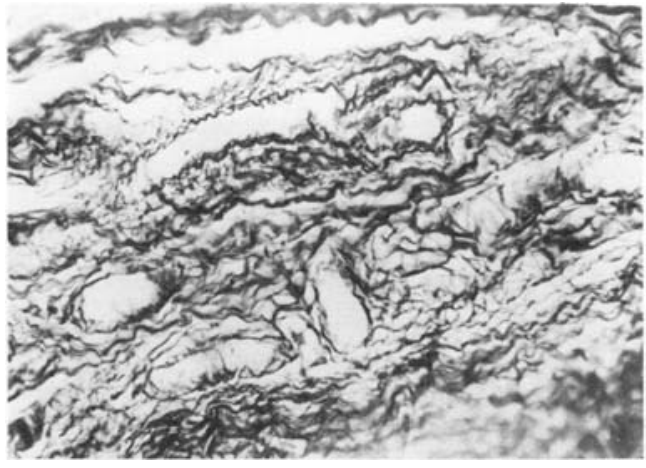

$\mathrm{b}$

Figure 1. (K/63) (a) Group II: B-glucuronidase activity in inflammatory cells, mainly large mononuclears, in the centre of a destroyed funiculus from the radial cutaneous nerve, the periphery of which is also fibrosed. (b) Same nerve as above, showing irregular reticulum framework in a nerve bundle which showed both inflammation and fibrosis. Note the vascular and perivascular reticulin of proliferated blood vessels. ((a) Longitudinal section stained by Hayashi's method for B-glucuronidase, on frozen sections, $\times 158$; (b) Gomori's reticulin, $\times 158)$.

the greater part of the nerve parenchyma has degenerated and is being replaced by myelinic figures. The change was found to involve Schwann cells of unmyelinated fibres essentially, and some of these fibres also manifested regeneration in the form of dense groups of very small but intact unmyelinated axons (RS, in Fig. 2 (c)). Here a vacuolated macrophage (M) is also seen. Figure 3 shows degeneration of the nerve fibres, particularly of the myelinated fibres, with an accumulation of reticulated osmiophilic material (left border of Fig. 3) within the Schwann cell around a still-existing myelin sheath. With more advanced degeneration the endoneurium becomes studded with tissue breakdown products.

In overtly TT- or BT-type cases of some duration (Group II), small mononuclear cells, representing one or another kind of lymphocyte, and large mononuclear cells with abundant cytoplasm with vacuoles containing finely granular material and a pale indented nucleus, representing epithelioid cells, can be seen within and between nerve funiculi. Such 'tuberculoid' exudate was generally encountered in the midst of necrotic tissue, as in Figure 4 (a). While muscle histology, histochemistry, and fine structure in these 4 groups of cases have been reported earlier, ${ }^{3,8}$ it is relevant to record the frequent neurogenic atrophy and the less frequent inflammatory infiltration between the muscle fibres that occurs in such cases (Fig. 4 (b)). Such infiltrates in the muscle are usually perineural and perivascular (arrows, Fig. 4 (b)), and arise from the main intra-neural inflammation. ${ }^{2,}$, 9, 10 The ulnar nerve in this case was thickened throughout its extent.

In untreated lepromatous leprosy the heavily bacillated Schwann cells and infiltrating macrophages show a lot of lysosomal enzyme activity (as seen in 


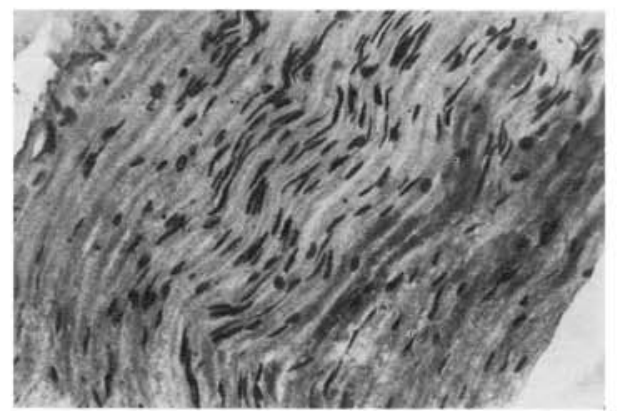

a

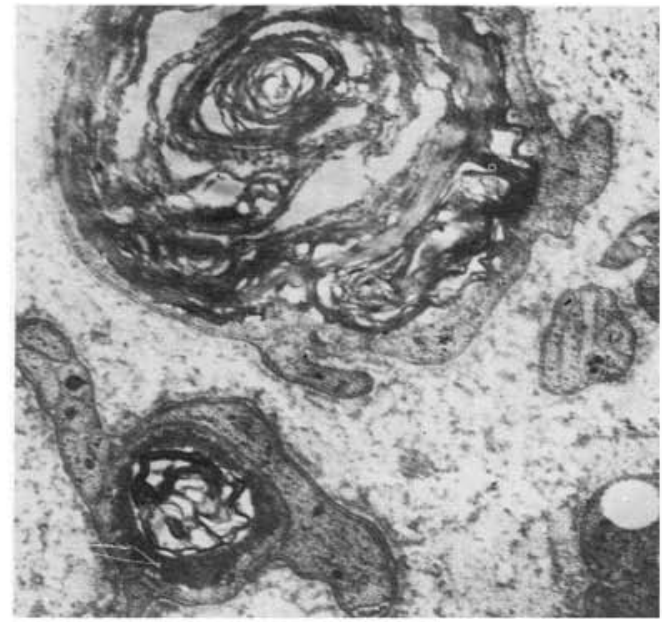

b

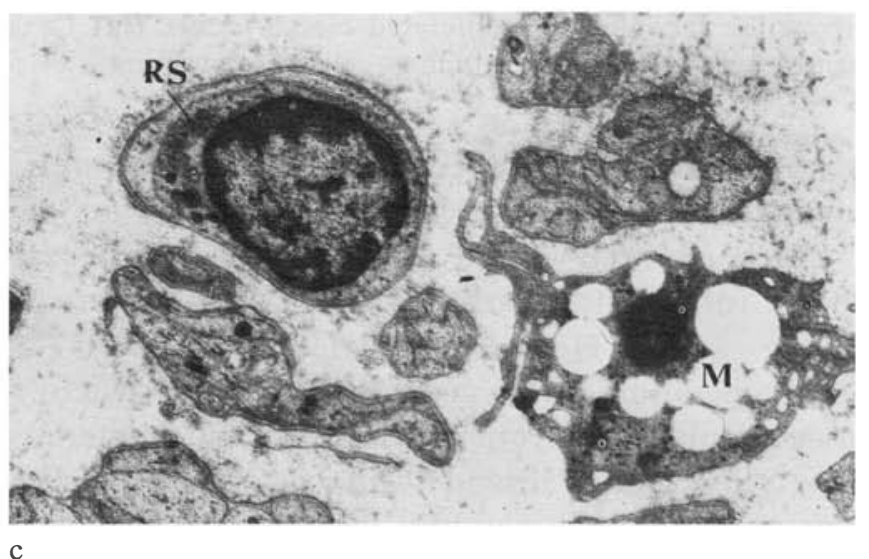

Figure 2. (a) (I/674) Group I: Medial funiculus of unaffected ulnar nerve at the elbow, showing central stream of increased nerve sheath (mainly Schwann cell) nuclei. (Frozen section, Hematoxylin and Eosin (H\&E), x 150.) (b) (J/557) Group I: Radial cutaneous nerve. Large and small myelinic figures occupying the greater part of 2 Schwann cells with only a few small unmyelinated axons remaining along the periphery. (c) Another part of same nerve showing possibly regenerating groups of very small unmyelinated axons. Note the possibly regenerating nucleated Schwann cell (RS) inside the older paler Schwann cell; and the vacuolated macrophage (M) with filipodia. (Osmicated araldite section stained with uranyl acetate and lead citrate; (b) $\times 9610$; (c) $\times 11,676$.)

Fig. 5 in Ref. 7). In treated lepromatous leprosy, where the bacilli tend to be fewer, the enzyme product is often seen along the periphery of distended, at times vacuolated, Schwann cells. This is seen with B-glucuronidase in Figure 5. When a concurrent bacillary stain is carried out on an enzyme preparation the bacilli are seen to remain intact and the Schwann cell alone shows the enzyme product (Fig. 5). There was no evidence of either of these 2 lysosomal enzymes being on the bacilli. 


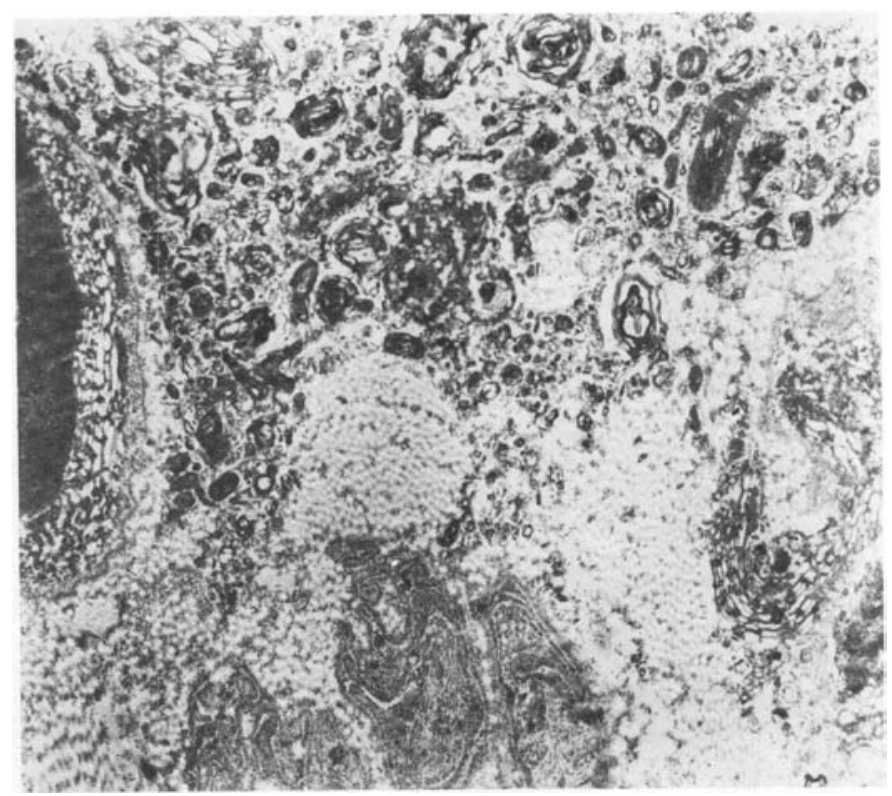

Figure 3. (I/976) Group I: Affected part of the nerve showing more fragmented osmiophilic debris, fewer fibres and more collagen. (Same as in Fig. 2, $\times 8,820$.)

In both treated and untreated lepromatous leprosy, macrophages are sometimes prominent. In Figure 6 there is a macrophage lying free in the endoneurial collagen and containing lysosomal bodies (L). There is also a small, possibly regenerating, Schwann cell (RS) within the larger Schwann cell (arrows) bearing a large axon (A) and a prominent lysosomal profile (L). Bacilli (B) are seen in the peripheral cytoplasm of the old Schwann cell as well as of the new. Such bacilli are still intact in their respective spaces or halos. In some parts of nerves from patients with treated lepromatous leprosy the Schwann cells showed many crumpled degenerate forms of bacilli (arrows, Fig. 7) and a number of empty lysosomal profiles (L, Fig. 7), with relatively few intact bacilli. Moreover, the entire Schwann cell of unmyelinated fibres in such nerves was found distended (SC, Fig. 7) and the clear spaces around individual bacilli had virtually disappeared. At times granular material representing primary lysosomes was also encountered in such distended Schwann cytoplasm of treated cases (Fig. 15 (b) in Ref. 7).

\section{INTRA-NEURAL VASCULAR AND INFLAMMATORY REACTION}

Even in early tuberculoid cases, without appreciable perivascular inflammatory cell reaction, the blood vessel showed evidence of increased transport of fluids across the endothelial cells and pericytes in the form of increased pinocytic vesicles in rows and clusters. The endothelial tight junctions tend to remain 


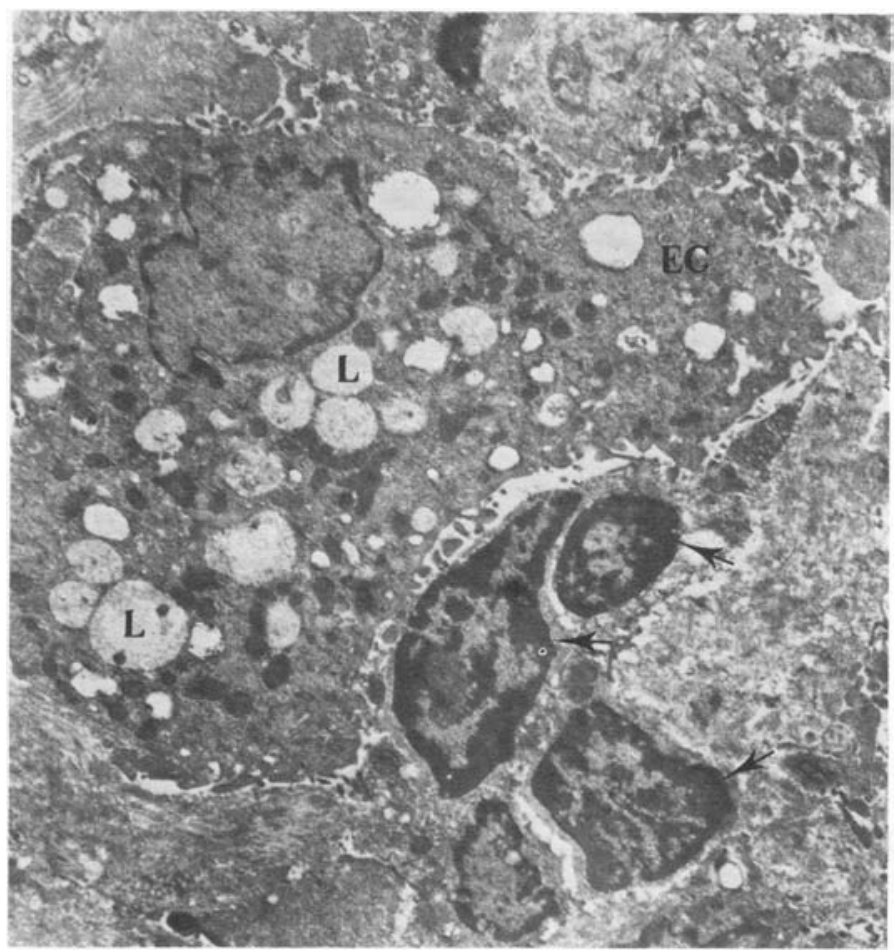

a

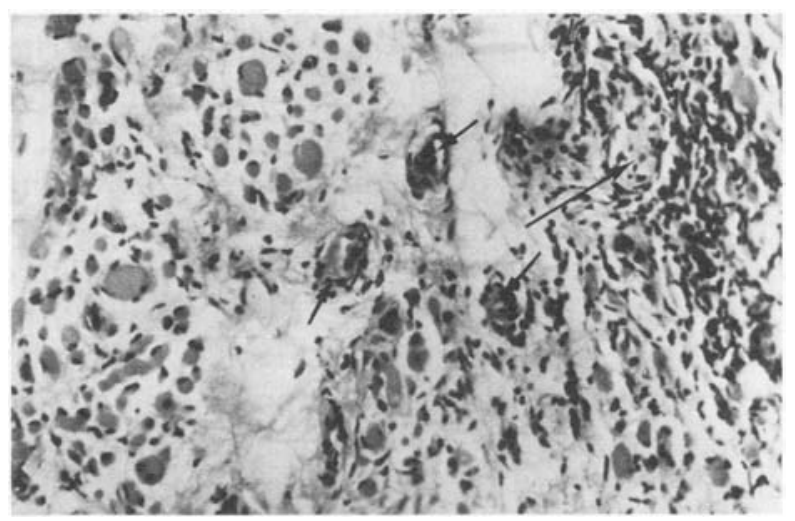

$\mathrm{b}$

Figure 4. (a) (J/763) Group II: The large mononuclear cell at the top is probably an epithelioid cell (EC), with many pale bodies containing finely granular material, probably lysosomes (L). The 4 small nuclei grouped together possibly belong to lymphocytes (arrows) and the large indented nucleolated nucleus at lower right to another macrophage. The matrix has necrotic tissue and collagen. (b) (K/63) Group II: First dorsal interosseous muscle. Crosssection showing severe group atrophy of the 2 fascicles on the left. Note disorganization of fascicles on the right by inflammatory mononuclear cell infiltrates, which are predominantly around a small nerve twig (long arrow) or small blood vessels (short arrows). ((a) As in Fig. 2, $\times$ 4,830; (b) Haematoxylin and Eosin, x 180.) 


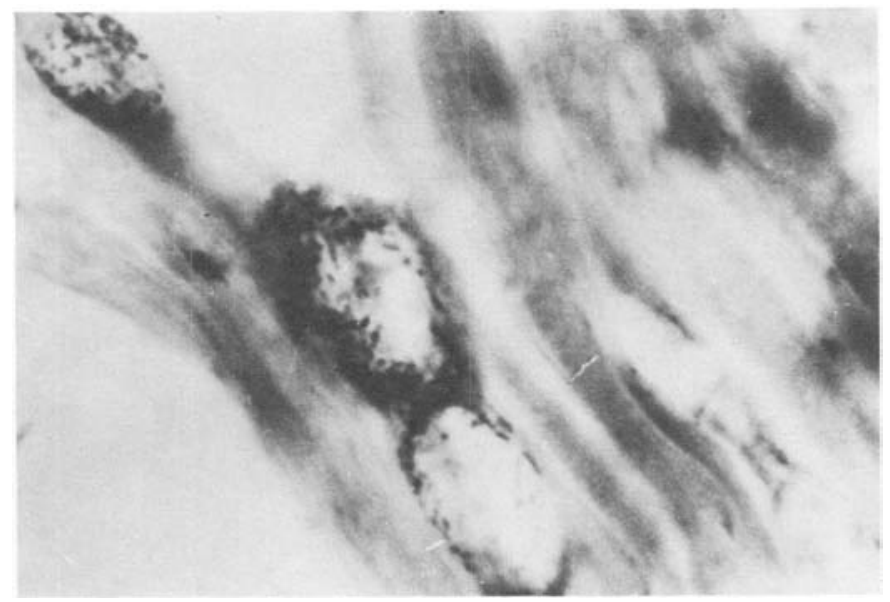

Figure 5. (J/299) Group IV: B-glucuronidase reaction product along the periphery of swollen Schwann cells containing intact acidfast bacilli. (As in Figure 1 (a) with superadded Fite-Faraco stain, $\times 1,120$.)

intact with the zonula occludens keeping shut along most of its course. A more advanced vascular change was the opening of gaps in the tight junctions, i.e. the formation of 'gap-junctions' (Fig. 17 (b) in Ref. 7). The small blood vessel outside the perineurium (P) in Figure 8 shows irregular and loosened contacts between endothelial cells and formation of oedema spaces between endothelial cells and pericytes, in addition to concentric proliferation of basement membranes (arrows).

In lepromatous leprosy, more frequently than in tuberculoid leprosy, mast cells were encountered both within and between the nerve funiculi. At times these cells were really large with abundant fuchsinophilic granulation, and were found in the vicinity of M. leprae, as in Figure 9 (a). Plasma cells were also found in lepromatous leprosy, though not as frequently as in the tuberculoid varieties. The perivascular location and pleomorphic appearance of macrophages can be noticed in Figure 9 (b), where the binucleate cell at the top with distended cisterns of endoplasmic reticulin (ER) filling its cytoplasm is quite unusual. Alternatively, it may be a very active plasma cell. In the centre of Figure 9 (b) the macrophage shows the more usual appearance with a number of lysosomes and phago-lysosomes (L), and one small group of probable degenerating bacilli (split arrows).

Dense perivascular inflammatory reaction by large and small mononuclear cells is seen in nerves from both established tuberculoid and established lepromatous cases. Actual infiltration of the vessel wall or vasculitis also occurs as in Figure 10 (a). In this nerve and in all such similar situations, copious perivascular reticulin fibres are laid down, and the endoneurial collagen also tends to be disorganized. A rather dramatic expression of perivascular macrophage reaction (arrows) and heavy bacillation in an area of loss of myelinated fibres 


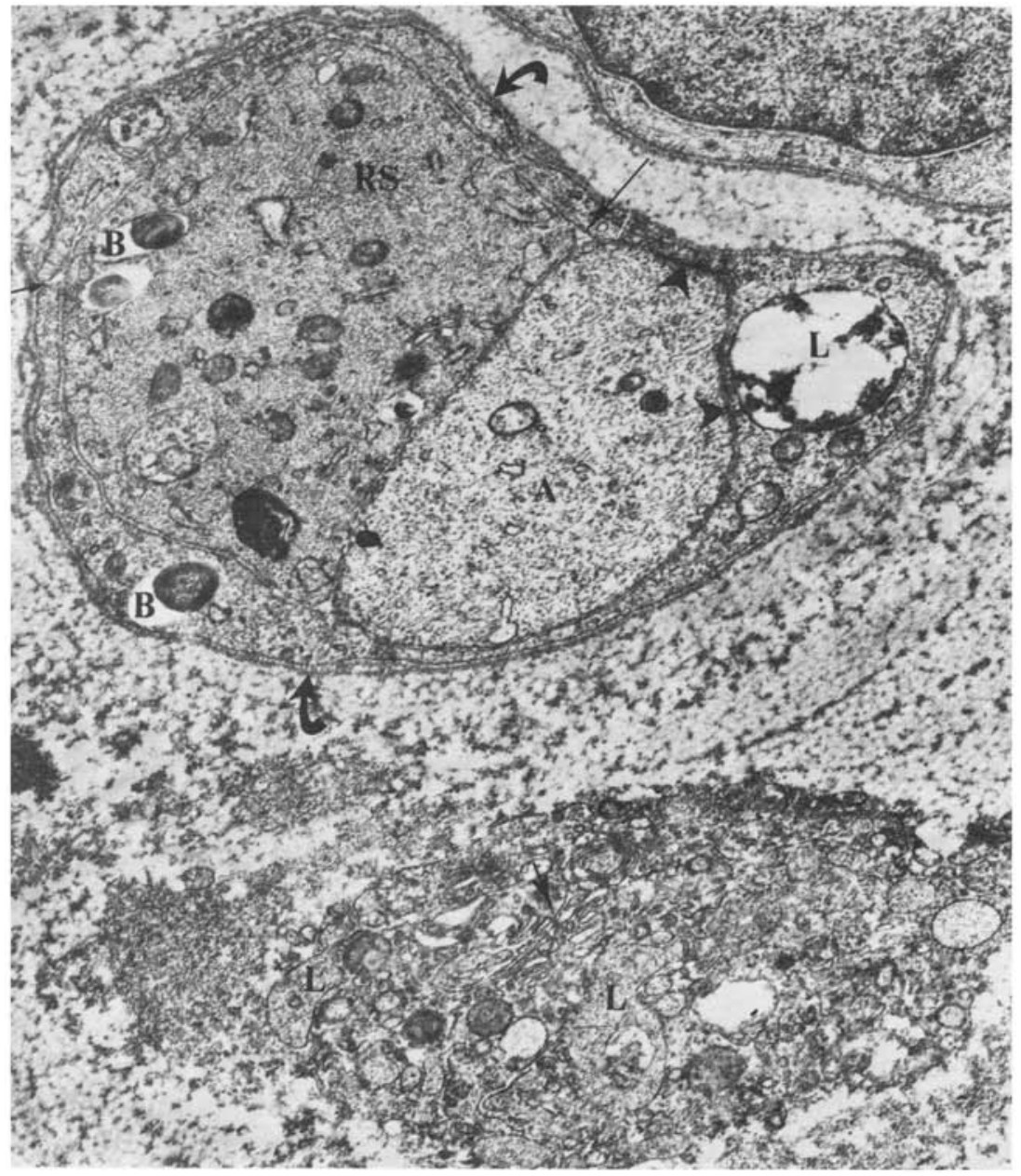

Figure 6. (I/746) Group III: Along the lower part of the picture is a macrophage showing Golgi tubules (arrow), lysosomal profiles (L) and vacuoles. The greater part of the picture is occupied by a large Schwann cell (curved arrows), with a break in its plasma membrane (small arrow), the greater part of it is occupied by another possibly regenerating Schwann cell (RS) with more organelles in its cytoplasm, containing a large axon (A) with possible myelination starting on one side (arrow heads), and the continuous membrane (long arrow) enclosing the cytoplasm and the axon of the inner Schwann cell. Note intact bacilli (B) in their respective spaces in the cytoplasm of both the old and the new Schwann cell and the large lysosome (L) containing osmiophilic debris in the old Schwann cell. (As in Fig. 2, $\times 14,490$.) 


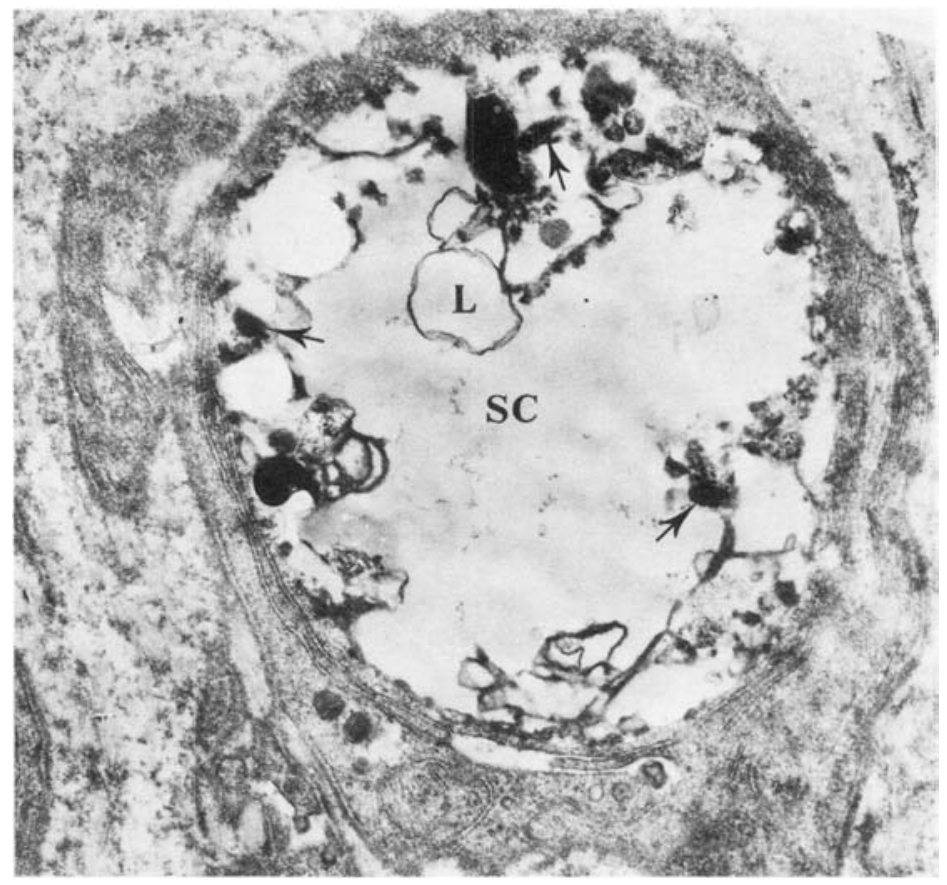

Figure 7. (J/107) Group IV: Nerve from treated lepromatous patient showing entire Schwann cell (SC) converted to a large space containing single membrane profiles of possible lysosomes (L), 2 intact osmiophilic bacilli and several degenerating bacilli (arrows). As in Fig. 2, × 15,498.)

in a nerve bundle is seen in Figure 10 (b). The centre of this lesion is formed of a small, thick-walled blood vessel and the periphery of fibroblast processes. It is of further interest that the large number of $M$. leprae encountered in this specimen was despite its being from a treated patient. At times large empty vacuoles (Fig. 11 (a)) in distended macrophages suggest large phagosomes earlier harbouring either bacilli or products of cellular degradation. The cytoplasm of such vacuolated macrophages (arrows, Fig. 11 (b)) manifests strong lysosomal enzyme activity.

Vascular and cellular reactions in and around the perineurium are a replica of those in the endoneurium, the perineurial cells being structurally comparable to the Schwann cells. An early reaction is a proliferation of perineurial cells which still retain their parallel alignment (P, Figs. 8 \& 12 (a)), when the interfunicular mononuclear cell exudate has not yet invaded the perineurium. With advancing disease the perineurial cells and their basement membrane thicken. They may show bacilli or empty vacuoles in lepromatous cases, and tend to disappear with replacement by macrophages, fibroblasts and collagen, as seen in Figure 12 (b), from a treated lepromatous patient (same nerve as in Figs. 5 \& 11 (a)). 


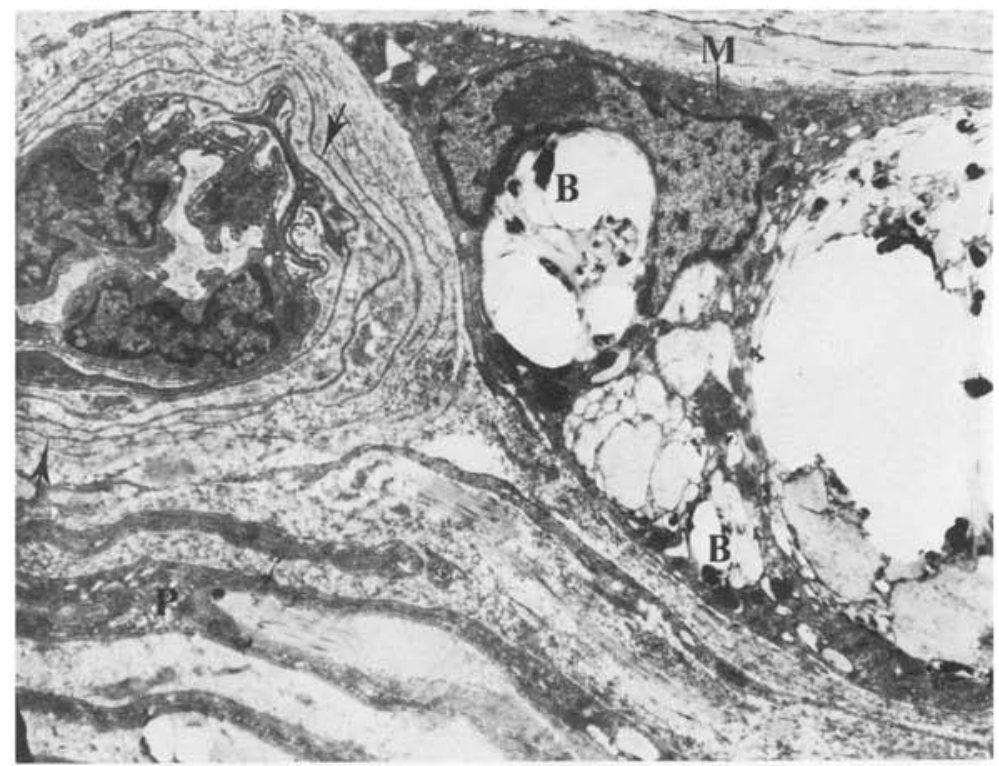

Figure 8. (J/107) Group IV: A blood vessel and a macrophage (M) just outside the thickened perineurium (P) of a nerve bundle. Note the intact bacilli (B) in the large and small vacuoles in the macrophage cytoplasm; and the oedema spaces between the endothelial cells and pericytes of the blood vessel, which shows proliferated BM laminae (arrows). (As in Fig. 2, $\times 3,535$.

\section{Discussion}

HISTOCHEMISTRY AND FINE STRUCTURAL COMPARISON OF MACROPHAGES AND SCHWANN CELLS, WITH SPECIAL REFERENCE TO MYCOBACTERIUM LEPRAE

One histochemical finding of the present study which merits a comment is the detection of the lysosomal enzyme B-glucuronidase only in the cytoplasm of the Schwann cells harbouring $M$. leprae, and not in the organisms. This fact was clearly brought out by the chemical analysis of lepromatous mouse tissue by

Figure 9. (a) (C/691): Ulnar nerve of untreated lepromatous patient (autopsy specimen) showing a large mast cell (arrow) with many granules and a number of intact rod forms of bacilli (small arrows). (b) (K/39) Group III: In the lower part of the picture is a small blood vessel with tight junctions (small arrows) between endothelial cells, and narrowed lumen (curved arrows). In the centre is a macrophage with 1 nucleus and cytoplasm showing many lysosomes (L) and a space containing 2 degraded bacilli (split arrows). Along the top of the picture is a large cell with 2 nucleolated nuclei and cytoplasm full of distended rough endoplasmic reticulum (ER): either an active macrophage or an active plasma cell. ((a) Paraffin section, Fite-Faraco's method, $\times$ 945; (b) As in Fig. 2, × 5,670.) 


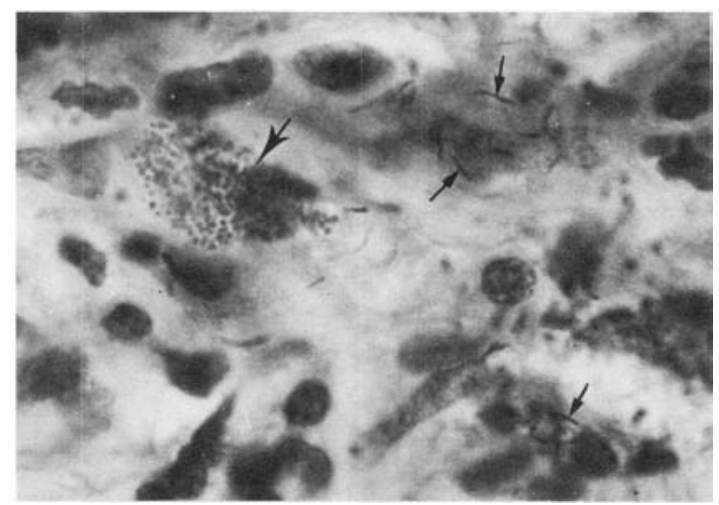

a

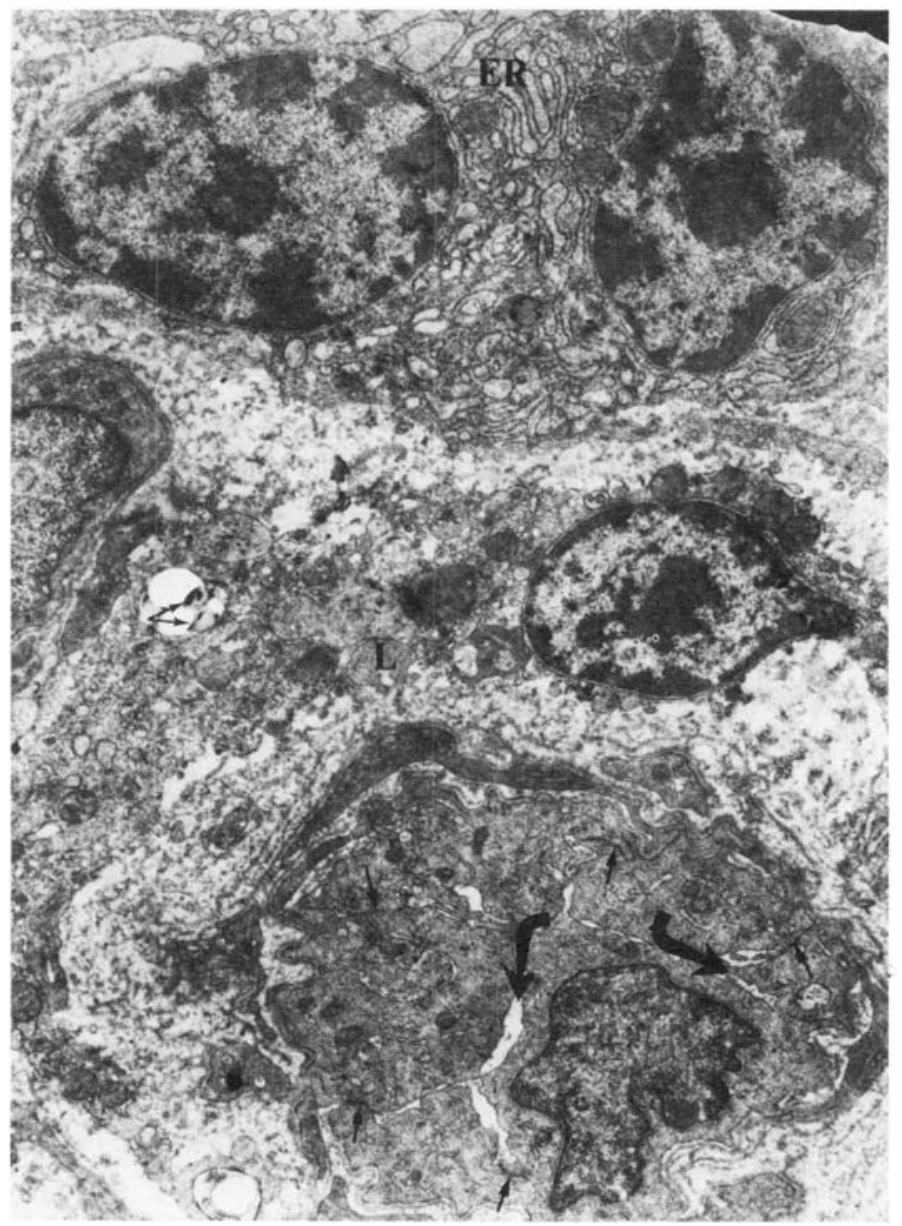



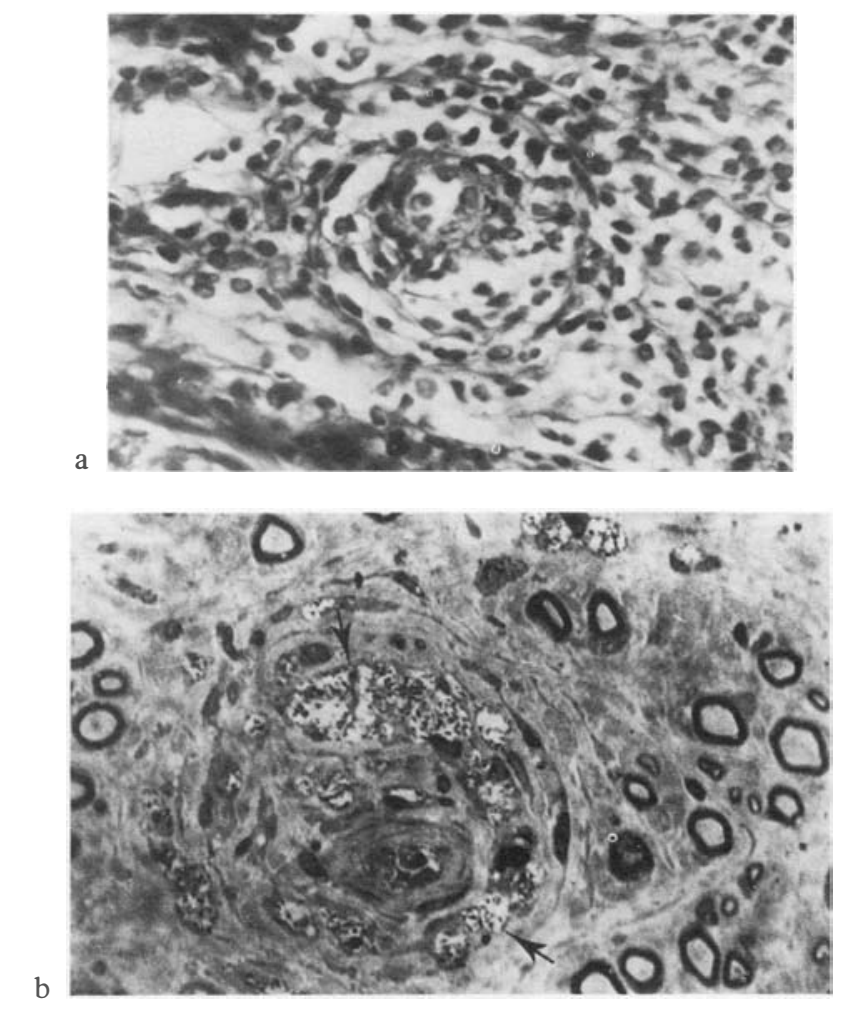

Figure 10. (J/201) Group IV: (a) Dense mononuclear cell infiltration filling a nerve bundle with clear vasculitis of the small central blood vessel. (b) Ring of distended macrophages full of bacilli, around a small central endoneurial blood vessel, in an area where the nerve fibres are destroyed. ((a) Picro-Mallory stain, $\times$ 403; (b) 1- $\mu$ m-thick osmicated araldite section stained with toluidine blue, $\times$ 532.)

Prabhakaran et al ${ }^{11}$ and recently confirmed, ${ }^{12}$ when this enzyme was detected exclusively in the host cell cytoplasm and not in the leprosy bacilli as suggested originally, by Skinsnes \& Matsuo. ${ }^{13}$ Another point of interest is that Bglucuronidase was also detected histochemically in Schwann cells and macrophages from our patients with non-lepromatous leprosy, just as acid phosphatase was found at these sites in our earlier study. ${ }^{14}$ Thus these lysosomal enzymes are not related to the presence of bacilli, but rather to the increased metabolic activity of Schwann cells and macrophages in all pathological states.

The fine structure of intraneural phagocytes other than Schwann cells, i.e. the macrophages, has been described here, because most of the earlier reports have confined themselves to macrophages in leprous skin lesions. ${ }^{15-18}$ They are described briefly in tuberculoid nerves ${ }^{19}$ lepromatous nerves ${ }^{20}$ and in leprous nerves and skin lesions. ${ }^{2,14}$ Very recently, Ridley et $a l^{21}$ have given a comprehensive electromicroscopic account of these mononuclear phagocytes across the immuno-histologic spectrum of leprosy, with emphasis on macro- 


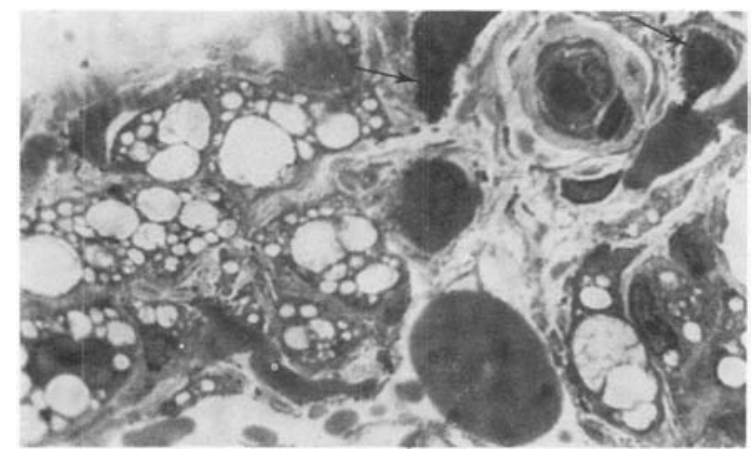

a

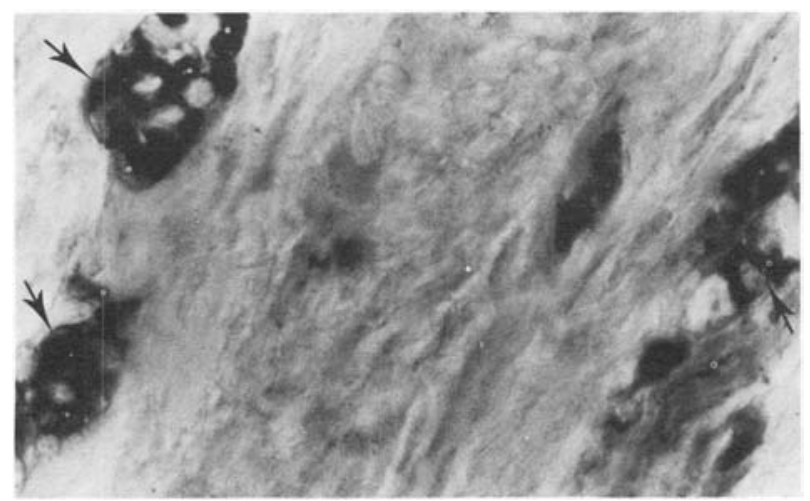

$\mathrm{b}$

Figure 11. (J/299) Group IV: (a) Clustering of highly vacuolated interfunicular macrophages. Note the small blood vessel at the top right, ringed by darker non-vacuolated mononuclear cells (arrows); note similarity of vacuoles to those in macrophage in Figure 8. (b) (J/107) Group IV: Acid phosphatase preparation on frozen section showing enzyme product in cytoplasm between vacuoles in the large macrophages (arrows), along the perineurium of the nerve bundle. ((a) As in Fig. 10 (b), x 945; (b) Gomori's acid phosphatase method, $\times$ 532.)

phages in borderline tuberculoid (BT) skin lesions. We have now stressed their appearance in the endoneurium and perineurium of nerves from very early nonlepromatous and treated or untreated lepromatous cases.

Irrespective of the type of leprosy, macrophages were usually fourid perivascularly, suggesting their origin from the blood monocyte; and were in larger numbers in the perineurium or just outside it, rather than in the endoneurium. In the latter situation the phagocytic propensity of Schwann cells for all particulate matter seemed to suffice. They seem capable of picking up virtually anything of a small enough size from their immediate environment. Thus in one study $^{22}$ carbon particles were phagocytosed by Schwann cells when injected within the perineurium, the cells of which too can ingest material like ferritin. ${ }^{23}$ The Schwann cells from human acoustic schwannomas avidly engulf mycobacteria such as M. leprae and the I.C.R.C. bacillus, even in short-term tissue cultures on standard media, and also show a positive reaction to lysosomal 

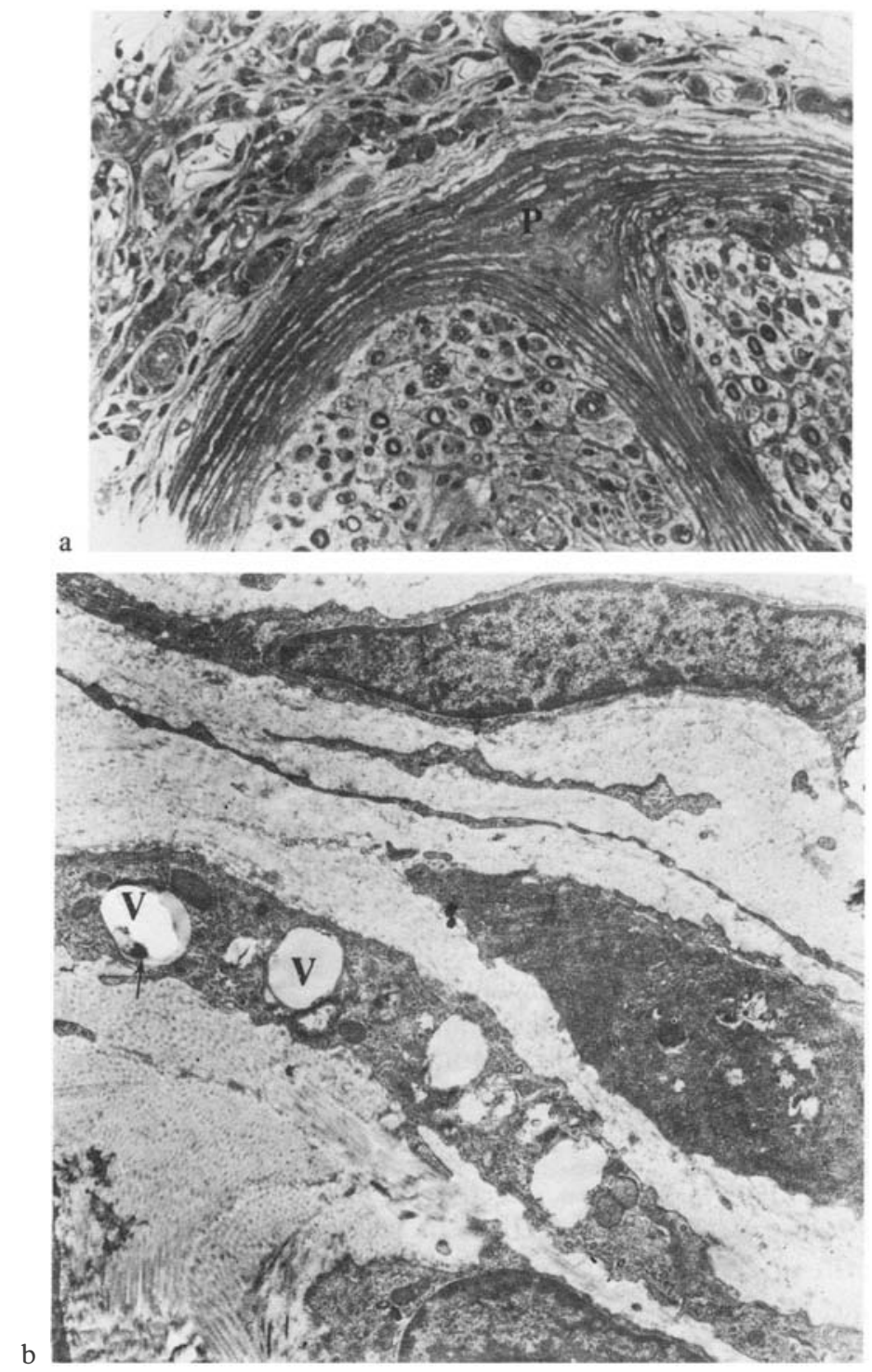

Figure 12. (K/39) Group III: (a) Many distinct layers of perineurial cells (P) enclosing and splitting a nerve bundle with depleted myelinated fibres. Note the dense vascular and mononuclear reaction outside the funiculus. (b) (J/299) Group IV: Perineural cells, increased fibroblasts and macrophages in dense collagenous matrix. Note degenerating bacillus (arrow) in one of the vacuoles (V) in a macrophage. ((a) As in Fig. 10 (b), $\times 200$; (b) As in Fig. 2, $\times 7,440$.)

enzymes. ${ }^{24}$ Human acoustic schwannomas rarely become melanotic when the tumour cells take up endogenously-produced melanin pigment. ${ }^{25}$

The cytoplasm of the macrophage was often highly vacuolated, especially in the treated lepromatous cases, where shrunken, possibly degenerating, and 
intact forms of bacilli were seen in these vacuoles or spaces. The appearances were comparable to those observed by us in macrophages of borderline lepromatous (BL) type of skin lesions (Figs. 11 (a), (b) in Ref. 14) and to the recent description of $\mathrm{BL}$ lesions by Ridley et al. ${ }^{21}$ However, many of the vacuoles in our treated lepromatous nerves or borderline skin lesions were empty or contained finely granular material and, to some extent, these macrophages came to resemble epithelioid cells in BT-type nerves, ${ }^{1,19}$ in BT-type skin lesions ${ }^{21}$ and in the very early non-lepromatous or established tuberculoid nerves (present study). Considered together with our histochemical findings, these vacuolar changes appear, at least in part, to be an expression of lysosomal enzyme activity. The fine structure and behaviour of lysosomes in disorders of infection and tissue breakdown, such as leprous neuritis and cerebral tuberculous lesions, has been discussed elsewhere. ${ }^{26}$

Both live and killed $M$. leprae are probably immunogenic. In fact, Rook ${ }^{27}$ has adduced evidence that the killing of leprosy bacilli might enhance their immunogenicity, because killed organisms may not be able to get into 'hiding places' such as the Schwann cells of peripheral nerves, but are taken up into the phagosomes of macrophages. Ever since histopathologists have seen bacilli along nerve fibre pathways, i.e. Schwann cells, by light microscopy $9,10,28,29$ they have been impressed by their large number and good preservation. They were believed to be sheltered from drugs and antibodies circulating in the blood. Electromicroscopy with modern methods has revealed, however, both intact and degenerating forms of bacilli within Schwann cells of lepromatous nerves $^{20,30}$ and we have presented evidence of bacterial degradation in and around lysosomes in Schwann cells, perineurial cells and intraneural endothelial cells, ${ }^{1,20}$ to the extent that in both treated and untreated cases the entire Schwann cell may look like a large phago-lysosome ${ }^{7,20}$ (and this paper). Moreover, on histochemical and fine structural evidence the behaviour of Schwann cells towards microbes or tissue breakdown products comes to resemble that of macrophages in nerves or skin lesions. ${ }^{2,6,7,14}$ Thus the Schwann cells of lepromatous nerves, especially in treated patients, may be capable at least to some degree, of 'processing' bacillary antigen, especially from killed $M$. leprae which are not insulated in their own little spaces, and presenting them to the antigen-recognizing system of the host, as the macrophages do. Hence the Schwann cell cytoplasm may not be a site as 'immunologically privileged' as believed hitherto. ${ }^{27}$

\section{POSSIBLE ROLE OF NON-BACTERIAL ANTIGENS IN NERVE DAMAGE}

One of the features revealed by the foregoing brief illustrated review of fine structure of the nerves in very early non-lepromatous leprosy is that an appreciable breakdown of nerve parenchyma, including axis cylinders, myelin sheaths and Schwann cytoplasm, can take place in the absence of bacilli and 
virtually of inflammatory changes or any corresponding sensory or motor deficit. It has also been seen that changes in the vessel wall, including the endothelial cells, tight junctions, pericytes and basement membrane can occur. An attempt has to be made to explain the pathogenesis of these changes. The histopathology of the skin lesions in these cases indicated a dermatitis with chronic inflammatory and occasionally granulomatous reaction, consistent with non-lepromatous leprosy. Despite the absence of acid-fast bacilli in all nerves and skin lesions examined from this group of patients, it has to be conceded that the initiation of the pathologic process must be through the host's own cell-mediated immune reactions to M. leprae. However, one has to look out for potentially immunogenic non-bacterial tissue components which may perpetuate nerve tissue destruction. Two such components which one has encountered in the present material are (i) the myelin sheath, and (ii) the vascular basement membrane.

The myelin sheath's basic protein has been recognized as a potent immunogenic substance since its demonstration as an essential component (along with Freund's adjuvant) in the production of experimental allergic encephalomyelitis (EAE) when CNS white matter is used, ${ }^{31}$ and of experimental allergic neuritis (EAN) when peripheral nerve myelin is used. ${ }^{32}$ We have found a similar mechanism working in tuberculous encephalopathy in some children with tuberculous meningitis where the brain damage is greater, the meningeal reaction not very severe and tubercle bacilli rarely demonstrated. $.^{33}, 34$ Wisniewsky and Bloom ${ }^{35}$ demonstrated, through an elegant series of experiments using sensitized animals with various forms of tuberculo-protein, that demyelination occurred at sites of lymphocyte and macrophage infiltration in the brain, spinal cord and peripheral nerves. They discussed the implications of the findings to both tuberculous meningitis and leprous neuritis. On the basis of the electronmicroscopic observations on non-lepromatous nerves reported here and published earlier, ${ }^{1,19}$ and supported by our earlier histological and histochemical findings, ${ }^{6,10}$ we have indirect evidence to suggest that products of nerve tissue breakdown, probably proteinous, can evoke a further hypersensitivity reaction and thereby perpetuate the nerve-damaging process initiated by the bacilli. Lumsden ${ }^{36}$ had advanced a similar view on theoretical considerations. Thus further nerve damage could result as an auto-immune disturbance without the mediation of bacilli. ${ }^{1}$

Passing reference must be made to the production of granulomatous lesions in rabbits by the use of human sensory nerve extract with Freund's adjuvant. ${ }^{37}$ Hardwicke and Crawford ${ }^{38}$ have shown recently that the antigenic fraction is located in the 'nuclear' fraction of the non-myelin component of sensory nerve and that it is not a lipid. While it is difficult to appreciate the specificity of nuclear fractions of sensory nerves as against motor nerves or mixed nerves, the fact remains that the earliest change in nerve fibres in any form of neuropathy, including leprous, even when there is no clinical deficit and no inflammatory reaction, is an increase in nerve sheath nuclei (as in Fig. 2 (a)). 
In both lepromatous neuritis (Groups III \& IV) and in the clinically silent neuropathy of very early cases of leprosy (Group I), another likely non-bacterial antigen that suggested itself is the perivascular basement membrane material that had frequently proliferated in several layers. Vascular and perivascular reticulin is probably the structural substrate of the basement membranes seen on the electronmicroscope. ${ }^{39} \mathrm{We}$, too, have evidence from examination of the reactive zone of brain tuberculomas that the copious basement membrane material around blood vessels is mainly reticulin; rather than periodic acid schiff (PAS) positive or alcian-blue positive substance which give fainter reactions. ${ }^{40}$

Among the vascular changes a feature of pathogenetic significance is the loosening of endothelial tight junctions, and at times the formation of gap junctions with the presence of plasmatous material outside such blood vessels. This obvious breaching of the blood-nerve barrier in respect of the endoneurial blood vessels finds a reflection in the experimental demonstration by Boddingius $e t a l^{41}$ of the seepage outwards of proteins and dyes injected intravenously in mice heavily infected with $M$. leprae. Moreover, both Boddingius ${ }^{42}$ and $\mathrm{we}^{2,19}$ have observed the proliferation of basement membranes of intraneural blood vessels in the tuberculoid varieties of leprosy also and, in the present study, even in nerves from cases with very early non-lepromatous leprosy. Such proliferated basal laminae may represent attempts at repair of a 'damaged' vessel in any condition, and one source of their origin may be the blood itself, as discussed elsewhere. ${ }^{40}$ Exuded plasma proteins naturally produce intra-neural oedema, which could constitute another mechanism of nervefibre damage. This could assume a more ominous significance in lepromatous nerves where the level of circulating antibodies is elevated. We have invoked the possibility of this mechanism as one explanation for the considerable musclefibre degeneration we encountered (in addition to atrophy), in the virtual absence of bacilli within muscle fibres, in the lepromatous patients of Groups III and IV, who actually showed higher levels of serum IgG. ${ }^{8}$

\section{Acknowledgements}

This work was supported by successive Research Grants from the American Leprosy Missions, Inc., New York; Sir Hormusji and Lady Manekbai Mody Trust, Bombay; and the Bombay Hospital Trust of the Medical Research Centre, Bombay.

Thanks are due to the Tata Institute of Fundamental Research for permitting generous use of their electronmicroscope; to Mr N Solanki for the printing of photomicrographs and electronmicrographs and to Mr A D'Souza for the typing. Special acknowledgement is due to my colleague Dr Daya Manghani for help in organizing the material. 


\section{References}

1 Dastur DK. The nervous system in leprosy. In: Goldensohn ES, Appel SH, eds. Scientific Approaches to Clinical Neurology. New York: Lea \& Febiger, 1977; 2: 1456-93.

2 Dastur DK. Leprosy (An infectious and immunological disorder of the nervous system). In: Vinken PJ, Bruyn GW, eds. Handbook of Clinical Neurology. New York: NorthHolland Publishing Company, 1978; 33: 421-68.

${ }^{3}$ Daver SM, Dastur DK, Ravenkar CR, Shah JS. Striated muscle in 4 categories of leprosy. I: Histology and histochemistry. Int J Lepr, 1980; 48: 140-8.

${ }^{4}$ Gomori G. Microscopic histochemistry: Principles and Practice. Chicago: University of Chicago Press, 1952.

5 Hayashi M, Nakajima Y, Fishman WH. Nephthol AS-BI-glucuronide method. J. Histochem Cytochem, 1964; 12: 293.

6 Dastur DK, Dabholkar AS. Histochemistry of leprous nerves and skin lesions: Acid phosphatase. J Path, 1974; 113: 69-77.

${ }^{7}$ Dastur DK, Porwal, GL. Lepromatous leprosy as a model of Schwann cell pathology and lysosomal activity. Clin and Exp Neurol. Proceedings of the Australian Association of Neurologists, 1979; 16: 277-93.

8 Dastur DK, Daver SM. Striated muscle in 4 categories of leprosy. II: Fine structural changes. Int J Lepr, 1980; 48: 149-58.

9 Dastur DK. The motor unit in leprous neutritis: A clinicopathological study. Neurology (India), 1956; 4: 1-27.

10 Dastur DK. The peripheral neuropathology of leprosy. In: Antia, NH, Dastur DK, eds. Symposium on Leprosy. Bombay: Bombay University Press, 1967; 57-71.

11 Prabhakaran K, Harris EB, Kirchheimer WF. B-Glucuronidase of mouse foot-pads infected with M-leprae and M-leprae separated from Armadillo tissues. Lepr. Memorabilia, 1976; 808: 1 .

12 Prabhakaran K. 1981 (Personal communication).

13 Skinsnes OK, Matsuo E. Acid mucopolysaccharide metabolism in leprosy. I: Storage of hyaluronic acid and its possible significance in the pathogenesis of leprosy. Int J Lepr, 1974, 42: 392-8.

14 Dastur DK, Ramamohan Y, Dabholkar AS. Some neuropathologic and cellular aspects of leprosy, In: Jucker E, ed. Progress Research. Basle: Birkhauser, 1974; 18; 53-75.

15 Brieger EM. The fine structure of the lepra cell. Trans Roy Soc trop Med Hyg, 1959; 53: $346-8$.

16 Nishiura M. The electronmicroscopic basis of the pathology of leprosy. Int J Lepr, 1960; 28: $357-400$.

17 Imaeda T, Convit J. Electronmicroscopic study of cutaneous nerves in leprosy. Int $J$ Lepr, 1963; 31: 188-210.

18 Aquino TI, Skinsnes OK. Pathobiologic significance of the subcellular organelles of lepra cells. Int J Lepr, 1970; 38: 134-48.

19 Dastur DK, Ramamohan Y, Shah JS. Ultrastructure of nerves in tuberculoid leprosy. Neurology (India), 1972; 20: 89-99.

20 Dastur DK, Ramamohan Y, Shah JS. Ultrastructure of lepromatous nerves, Neural pathogenesis in leprosy. Int J Lepr, 1973; 41: 47-80.

21 Ridley MJ, Badenoch-Jones P, Turk JL. Ultrastructure of cells of the mononuclear phagocy te series (MPS) across the leprosy spectrum. $J$ Path 1980; 130: 223-7.

22 Palmer E, Rees RJW, Weddell AGM. The phagocytic activity of Schwann cells. In: Cytology of Nervous Tissue. Report Ann. Mtg. Anatomical Soc. 1961; 49. 
${ }^{23}$ Waggener JD, Bunn SM, Beggs J. The diffusion of ferritin within the peripheral nerve sheath. An electronmicroscope study. J Neuropath exp Neurol, 1965; 24: 430-43.

Lalitha VS, Bapat CV, Dastur DK. Culture and Phagocytic characteristics of Schwann cells in vitro. A possible model substrate for cultivation of M-leprae. Int J Lepr, 1977; 45: $266-72$.

25 Dastur DK, Sinh G, Pandya SK. Melanotic tumor of the acoustic nerve. Case reports. $J$ Neurosurg, 1967; 27: 166-70.

26 Dastur DK. Fine structure of lysosomes in brain, nerve and muscle. In disorders of storage, infection and tissue breakdown. Trends in NeuroSciences, 1980; 3: 173-7.

27 Rook GAW. The immunogenicity of killed mycobacteria. Lepr Rev, 1980; 51: 295-301.

${ }^{28}$ Khanolkar VR. Studies in the histology of early lesions in leprosy. ICMR Special Report Series No. 19, 1951.

29 Lumsden CE. Leprosy and the Schwann cell in vivo and in vitro. In: Cochrane RG, Davey TF, eds. Leprosy in Theory and Practice. Bristol: John Wright \& Sons Ltd. 2nd edn. $1964 ; 221-50$.

30 Job CK. Mycobacterium leprae in nerve lesions in lepromatous leprosy - an electromicroscopic study. Arch Path, 1970; 89: 195-207.

31 Alvord EC. The etiology and pathogenesis of experimental allergic encephalomyelitis. In: Bailey OT, Smith DE, eds. The Central Nervous System - Some Experimental Models of Neurological Disease. Baltimore: Williams \& Wilkins, 1968; 52-70.

32 Waksman BH, Adams RD. An experimental disease of rabbits induced by the injection of peripheral nerve tissue and adjuvants. J Exp Med, 1955; 102: 213.

33 Dastur DK, Udani PM. Pathology and pathogenesis of tuberculous encephalopathy: Acta Neuropath, 1966; 6: 311-26.

34 Dastur DK, Lalitha VS. The many facets of neurotuberculosis: An epitome of neuropathology. In: Zimmerman HM, ed. Progress in Neuropathology. New York: Grune \& Stratton, Inc., 1973; 2: 351-408.

35 Wisniewski HM, Bloom BR. Primary demyelination as a non-specific consequence of a cell-mediated immune reaction. $J$ exp Med, 1975; 141: 346-59.

${ }^{36}$ Lumsden CE. Discussion of paper by Weddell, Palmer, Rees and Jamison. In: Wolstenholme GE, O'Connor M. eds. The Pathogenesis of Leprosy. London: Ciba Foundation Study Group. No. 15, 1963; 15.

37 Crawford CL, Hardwicke PMD, Evans DHL, Evans EM. Granulomatous hypersensitivity induced by sensory peripheral nerve. Nature, 1977; 265: 457-9.

38 Hardwicke PMD, Crawford CL. Nature of the antigen of human sensory nerve that induces granulomatous hypersensitivity. J Neurochem, 1978; 30: 1609-11.

39 Cervos-Navarro J, Matakas F. The ultrastructure of reticulin. Acta Neuropath (Berl), $1975 ; 6: 173-6$.

40 Dastur DK, Dave UP. Ultrastructural basis of the vasculopathy in and around brain tuberculomas: Possible significance of altered basement membrane. Amer J Path, 1977; 89: 35-50.

41 Boddingius J, Rees RJW, Weddell AGM. Defects in the bloodnerve barrier in mice with leprosy neuropathy. Nature, 1972; 237: 190-1.

42 Boddingius J. Ultrastructural changes in blood vessels of peripheral nerves in leprosy neuropathy. I: Tuberculoid and borderline tuberculoid leprosy patients. Acta Neuropath (Berl), 1976; 35: 159-81. 